\title{
Physical activity levels objectively measured (cossuak among older adults: a population-based study in a Southern city of Brazil
}

Virgílio Viana Ramires ${ }^{1,2,3^{*}}$, Fernando César Wehrmeister ${ }^{1}$, Andrea Wendt Böhm,3 Leony Galliano ${ }^{4,3}$, Ulf Ekelund ${ }^{5,6}$, Soren Brage ${ }^{5}$ and Inácio Crochemore Mohnsam da Silva ${ }^{1,3,7}$

\begin{abstract}
Background: Low levels of physical activity are currently observed in all age groups around the world. Among older adults physical activity is even lower, potentially influencing quality of life, incidence of diseases and premature mortality. The aim of this study was to describe objectively measured physical activity levels among older adults residents in a Southern city of Brazil.

Methods: A population-based study was carried out including people aged 60+ years living in the urban area of Pelotas. Face-to-face interviews, anthropometric measures and triaxial accelerometry (non-dominant wrist) were used to collect sociodemographic, anthropometric and physical activity, respectively. For descriptive purposes, overall physical activity was expressed as daily averages of acceleration. Time spent in light physical activity (LPA) and moderate-to-vigorous physical activity (MVPA) using different bout criteria (non-bouted, and in 1-, 5- and 10-min bouts) were calculated. Crude and adjusted analyses were performed using simple linear regression to examine the association between physical activity and exposure variables.

Results: Overall, 971 individuals provided valid accelerometry data. Women spent on average more time on LPA (136.2 vs. 127.6 min per day). Men and women respectively accumulated, in average, 64.5 and 56.7 min per day of non-bouted MVPA, while these daily averages were 14.9 and 9.46 min using 5-min, and 8.1 and 4.5 min using 10-min bout MVPA. In adjusted analyses, men aged 80 years or more spent in average 45 min less LPA per day when compared to men 60-69 years and, among women, this difference was $65 \mathrm{~min}$. Considering time in 5-min MVPA bouts, the youngest age group and those with a better self-perceived health accumulated more MVPA. Specifically among men, socioeconomic status was inversely associated with 5-min bout MVPA.
\end{abstract}

Conclusion: The present study showed low levels of physical activity among Brazilian older adults, even lower in more advanced ages, and a different pattern for physical activity intensity between men and women.

Keywords: Population-based study, Older adults, Physical activity and accelerometry

\footnotetext{
*Correspondence: virgilioramires@hotmail.com

${ }^{1}$ Postgraduate Program in Epidemiology, Federal University of Pelotas,

Marechal Deodoro, 1160 - 3 Piso, Centro, 96020-220, Pelotas, Brazil

${ }^{2}$ Federal Institution for Education, Science and Technology, Camaquã

Campus, Camaquã, Brazil

Full list of author information is available at the end of the article
} 


\section{Background}

The low levels of physical activity currently observed in all age groups around the world [1] are a concerning scenario in terms of public health, although less objective data are available in low-middle income countries. There is a large amount of evidence highlighting physical inactivity as an important risk factor for many chronic diseases [2]. Specifically in the older adults population, levels of physical activity tend to be even lower than in adults [3]. Although lower levels of physical activity influence a higher incidence of diseases and premature mortality, adequate levels of physical activity might play an important role in healthy aging [4].

Rapid demographic transitions experienced by lowand middle-income countries have been marked by the challenge regarding aging with basic quality of life [5]. Further, accurate physical activity estimates, especially in these countries, are scarce providing a limited diagnosis of physical activity levels. Due to lower complexity and relative low cost, most studies use subjective methods, such as questionnaires, to assess physical activity $[6,7]$. However, among older adults population, estimates provided by these methods present lower accuracy compared to objective measurement of physical activity [8]. In general, subjective methods tend to overestimate moderate and vigorous physical activity and underestimate sedentary behavior $[9,10]$ and associations with health outcomes tend to be stronger using objective measures [11].

In this context, the uses of objective methods are preferable for assessing physical activity patterns among the older adults [12]. Furthermore, descriptive studies are needed to accurately measure population physical activity levels, as well as their distribution across specific population strata which could be the target of interventions. Thus, the aim of this study was to describe physical activity, measured by accelerometers in a population-based sample of older adults residents in a Southern city of Brazil, highlighting differences among sexes, nutritional status and socioeconomic status.

\section{Methods}

\section{Sampling and study design}

A population-based study was carried out among older adults living in the urban area of Pelotas, Rio Grande do Sul state, Brazil. Pelotas is a southern city with around 340,000 inhabitants and approximately 46,000 people aged 60 years or older [13]. Its HDI is 0.74 , similar to the overall country. This study is part of a large survey which assesses general aspects of health in an older adults population. The data collection was conducted between January and August 2014 and individuals aged 60 years or older were considered older adults, according to recommendations of the World Health Organization (WHO) for low- and middle-income countries [14].

The sampling process was performed in two stages. First, a total of 488 census tracts from urban areas of Pelotas were sorted according to their average family income, based on the 2010 Demographic Census [13]. Census tracts presenting fewer than 15 older adults people were clustered. Therefore, from 469 census tracts listed, 133 were randomly selected. The second stage was the household selection within each census tract included in the survey. Based on the total number of inhabited households, a systematic selection was performed and all adults older than 60 years who were living in the selected households were invited to participate. The sampling process included 31 households per census tract and around 12 participants in each cluster were recruited.

\section{Data collection}

A trained team carried out face-to-face interviews including questions on sociodemographic and health information. Anthropometric measures were also performed. Weight was assessed using electronic scales (Tanita, model UM-080), which is able to handle up to $150 \mathrm{~kg}$ at a precision of $0.1 \mathrm{~kg}$. For estimation of height, a knee height measurement was applied with participants seated using infants anthropometric instrument (Indaiá). The final height was based on Chumlea e Guo [15] equations and this procedure is justified due to difficulties to sustain orthostatic posture in older adults population.

\section{Accelerometry}

Following the interview, participants were invited to wear an accelerometer on their non-dominant wrist for the next 7 days, $24 \mathrm{~h}$ per day, including during waterbased activities. The interviewers provided all important information regarding the devices and informed about a future call to schedule the accelerometer attachment. Participants wore the devices during seven consecutive days and the research team was responsible for attaching and collecting the accelerometers from the participants' households.

The accelerometer used was the GENEActiv ${ }^{\oplus}$ (Activinsights Ltd, Kimbolton, Cambs, UK, http://www.geneactiv.org), a water-proof device which measures acceleration in three axes and provides raw data expressed in gravitational equivalent units $(1000 m g=1 g)$. Accelerometers were initialized to collect data in $85.7 \mathrm{~Hz}$ time resolution. Bed-bound and disabled older adults were considered as exclusion criteria for the accelerometer measurement.

\section{Accelerometer data processing}

The GENEAcitiv software was used to set up and download accelerometers data. Raw data were calibrated to 
local gravity, scored for non-wear based on prolonged (>60 min) periods of low acceleration variability $(\mathrm{SD}<$ $13 \mathrm{mg}$ ), and abnormally high values were censored. Activity-related acceleration was calculated using the Euclidian Norm (vector magnitude of the three axes)


segments were imputed by the average of similar timeof-day data points from other days of the measurement (within individual). Activity intensity was estimated from 5-s aggregated time-series as average time per day spent in light, moderate and vigorous physical activities. Detailed information about these analytical procedures is available elsewhere [16-18]; these analyses were performed in R-package GGIR (http:/cran.r-project.org).

In the present study, overall physical activity is expressed by the daily average of acceleration. Light physical activity (LPA) was defined as activities representing acceleration between 50 and $99 \mathrm{mg}$, while activities with acceleration higher than $100 \mathrm{mg}$ were considered as moderate to vigorous physical activity (MVPA) $[16,19]$. Furthermore, specifically for MVPA, different bout criteria were adopted (non-bouted, 1-, 5- and $10 \mathrm{~min}$ bout). Bouts were defined as consecutive periods in which participants spent at least $80 \%$ of this time in MVPA. LPA (non-bouted) and MVPA in 5 min-bout were the main outcomes in the association analyses. Participants providing fewer than two days of measurement were excluded from the analyses.

\section{Complementary variables}

The following basic sociodemographic characteristics were assessed and categorized as follows: sex (men/ women); age (60-69; 70-79 e $\geq 80$ year); skin color (white/non-white); socioeconomic status (based on asset index and grouped as $\mathrm{A} / \mathrm{B}$ - richest, $\mathrm{C}$ and $\mathrm{D} / \mathrm{E}$ - poorest) [20]; marital status (single or married); occupational status (currently not working or currently working); self-perceived health (very good/good; regular and bad/very bad); and Body Mass Index (BMI - normal $<25 \mathrm{~kg} / \mathrm{m}^{2}$; overweight $>25$ and $<30 \mathrm{~kg} / \mathrm{m}^{2 ;}$ and obese $>$ $\left.30 \mathrm{~kg} / \mathrm{m}^{2}\right)$.

\section{Statistical analyses}

Sample descriptive analyses are presented based on relative and absolute frequencies. ANOVA and T-test or Kruskal Wallis and Wilcoxon non-parametric tests were performed in order to verify the average differences among dichotomized and ordinal variables, respectively. Crude and adjusted analyses were performed using simple linear regression to verify the association between physical activity and exposure variables. All analyses were stratified by sex and took the clustering of the sample into account. Analyses were carried out in Stata (version 12.1).
The present study was submitted and approved by the Ethics Research Committee of the Medical School of the Federal University of Pelotas according to the protocol number 201324538513.1.0000.5317. The confidentiality was guaranteed for all individual information and all participants signed the research consent.

\section{Results}

Among the 1844 older adults eligible to participate in the study, 1451 were interviewed. The losses and refusals (21.3\%) were similarly distributed in terms of sexes and age groups. Overall, 971 participants (66\%) had valid accelerometry data. The socioeconomic, behavioral and health characteristics from the general and analytic sample are showed in Table 1 . The analytical sample included more women (62.2\%), were between 60 and 69 years of age $(51.1 \%)$, white $(82.1 \%)$, living with a partner $(56.2 \%)$, retired (79.6\%), reported a socioeconomic status "C" (54.4\%), overweight (42.2\%), and a perception about their health classed as "good" (52.1\%).

The description and distribution of total, light and moderate to vigorous physical activity stratified by sex are showed in Fig. 1 and Table 2. In general, women spend more time on light intensity physical activity (136.2 vs. 127.6 min per day), while men spend more time on MVPA (15.0 vs. 8.1 min per day). Total physical activity did not differ between sexes $(22.0 \mathrm{vs}$. $21.5 \mathrm{mg}$ ).

Important differences were observed in MVPA in accordance to the different bout criteria (Fig. 2). When no bout criterion was used, men and women performed an average of 64.5 and $56.7 \mathrm{~min}$ per day of MVPA, respectively. However, when the 1-min bout criterion was considered, this estimate decreased by approximately $50 \%$. Finally, when the 5- and 10-min MVPA bouts were evaluated, the average daily time spent in these intensities were 14.9 and $9.5 \mathrm{~min}$ per day among men and 8.1 and 4.5 min per day among women, respectively.

Table 3 shows the association between socioeconomic status, behavioral and health characteristics with light intensity physical activity. Men aged 80 years or more spent on average 45 min less in LPA per day when compared to the $60-69$ yearsold age group. Among women, this difference was $65 \mathrm{~min}$. Furthermore, minutes spent in LPA were slightly lower (approximately $10 \mathrm{~min}$ ) among obese women and those single, compared to their counterparts. Older adults who reported being employed performed on average 20 min per day more of LPA than those who did not work. Men and women who considered their health bad or very bad accumulated in average 46 and $33 \mathrm{~min}$ less time per day spent in light intensity physical activity than those who considered their health very good or good, respectively. 
Table 1 Original and analytical sample characteristics according to sociodemographic and health characteristics - Pelotas/Brazil, 2014

\begin{tabular}{|c|c|c|c|}
\hline Characteristics & Total N (\%) & Analytical N (\%) & $p$-value \\
\hline Gender & & & 0.700 \\
\hline Male & $537(37.0)$ & $367(37.8)$ & \\
\hline Female & $914(63.0)$ & $604(62.2)$ & \\
\hline Age & & & 0.255 \\
\hline $60-69$ & $756(52.3)$ & $496(51.1)$ & \\
\hline $70-79$ & $460(31.8)$ & $337(34.7)$ & \\
\hline$\geq 80$ & 230(15.9) & 138(14.2) & \\
\hline Skin color & & & 0.301 \\
\hline White & $1211(83.7)$ & 797(82.1) & \\
\hline Not White & $236(16.3)$ & $174(17.9)$ & \\
\hline Marital Status & & & 0.090 \\
\hline Married & 763(52.7) & $546(56.2)$ & \\
\hline Single & $684(47.3)$ & $425(43.8)$ & \\
\hline Occupational Status & & & 0.320 \\
\hline Currently not working & 1084(80.4) & $728(79.6)$ & \\
\hline Currently working & 264(19.6) & 172(20.4) & \\
\hline Socioeconomic Status & & & $<0.001$ \\
\hline $\mathrm{A} / \mathrm{B}$ (richest) & $384(27.9)$ & $327(35.1)$ & \\
\hline C & $781(56.8)$ & $506(54.4)$ & \\
\hline $\mathrm{D} / \mathrm{E}$ (poorest) & 210(15.3) & $98(10.5)$ & \\
\hline Body Mass Índex (BMI) & & & 0.887 \\
\hline Normal $(\mathrm{BMl}<25$ kg/m²) & $385(28.2)$ & $259(27.3)$ & \\
\hline $\begin{array}{l}\text { Overweight } \\
\left(\mathrm{BMl}>25<30 \mathrm{~kg} / \mathrm{m}^{2}\right)\end{array}$ & $571(41.9)$ & $400(42.2)$ & \\
\hline Obese $\left(\mathrm{BMI}>30 \mathrm{~kg} / \mathrm{m}^{2}\right)$ & $408(29.9)$ & $289(30.5)$ & \\
\hline Self-perceived health & & & 0.885 \\
\hline Very good/ Good & 765(53.1) & $504(52.1)$ & \\
\hline Regular & $545(37.8)$ & $375(38.7)$ & \\
\hline Very bad/ Bad & $132(9.1)$ & $89(9.2)$ & \\
\hline
\end{tabular}

There was no difference between LPA and nutritional status and marital status among men; and between LPA and socioeconomic status among both men and women.

Table 4 shows the results from the association between MVPA and socio-demographic and health variables considering the 5- min bout criterion. Men and women aged 80 years or older performed on average 16 and 10 min less MVPA per day, respectively than the 60-69 years-old group. Men from less privileged social status were more active in MVPA in relation to the ones from higher social status (14 min on average), as well as those of normal weight in relation to those categorized as obese $(8 \mathrm{~min})$. Older adults with a very good or good self-reported health perception spent more time on MVPA than those who considered their health bad or very bad (16 min per day among men and 7 min per day among women).

\section{Discussion}

The present study described levels of physical activity objectively measured among older adults in a population-based sample from Brazil, providing relevant evidences from a middle-income country which are still scarce in the literature. The average time spent per day in MVPA was relatively low among older adults and varied according to different analytical procedures. Moreover, important differences were found in intensities of physical activity according to sexes. Women spent more time in LPA, while men accumulated more time of MVPA, similarly to studies from high-income settings $[3,21]$. The oldest participants, those currently not working (retired or unemployed) and reporting a poor self-perceived health presented lower levels of light and moderate to vigorous intensity physical activity.

The use of raw accelerometry presents many advances, such as transparency in the analytical process and enhanced comparability between data collected from

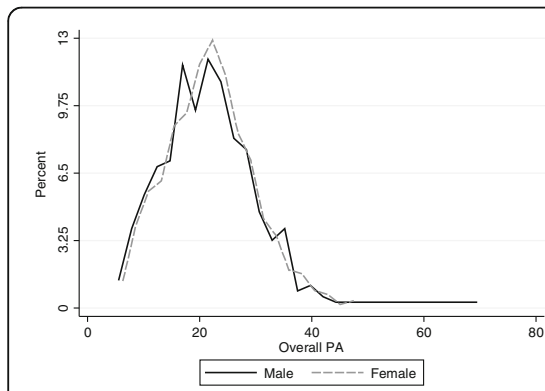

(a) Overall physical ${ }^{1}$

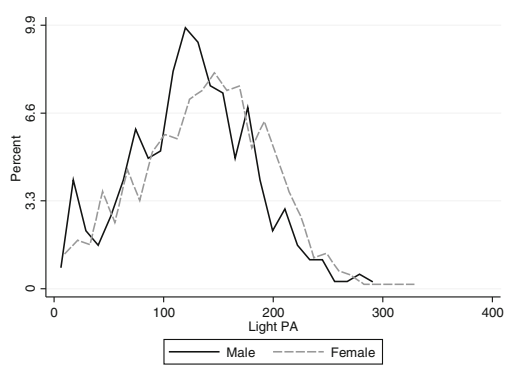

(b) Light physical activity ${ }^{2}$

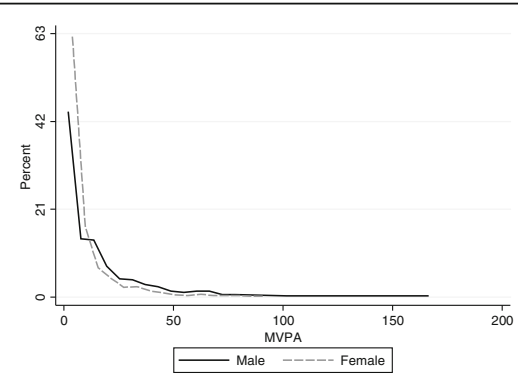

(c) Moderate-to-vigourous physical activity ${ }^{3}$

Fig. 1 Overall physical activity (a) and average time spent per day in light (b) and moderate-to-vigorous (c) physical activity among older adults according to sex - Pelotas/Brazil, 2014. Acceleration mean per day 1. Average minutes per day spent in light physical activity non-bouted criteria. 2. Average minutes per day spent in moderate-to-vigorous physical activity (5 min bout) 
Table 2 Descriptive of physical activity levels among older adults - Pelotas/Brazil, 2014

\begin{tabular}{|c|c|c|c|c|c|c|}
\hline & Overall PA (mg) Mean and 95\%Cl & $P * *$ & LPA (min/day) Mean and 95\%Cl & $P^{* *}$ &  & $P^{\#}$ \\
\hline Male & $22.0(21.2 ; 22.9)$ & 0.307 & $128(122 ; 133)$ & 0.024 & $15(13 ; 17)$ & $<0.001$ \\
\hline Female & $21.5(20.9 ; 22.1)$ & & $136(132 ; 140)$ & & $8(7 ; 9)$ & \\
\hline Total & $21.7(21.2 ; 22.2)$ & & $133(129 ; 136)$ & & $11(10 ; 12)$ & \\
\hline
\end{tabular}

MVPA moderate to vigorous physical activity, LPA light physical activity

${ }^{*}$ MVPA 5 min bout

** $T$ test

\# Wilcoxon rank-sum test

different devices; however, there are still only limited triaxial wrist acceleration data to compare current results to, owing to this attachment site only becoming more commonly used in very recent studies [12, 22]. Among older adults, a study with similar methodology was an English occupational cohort study [11] aimed to compare effects of physical activity on adiposity, measured by accelerometers and questionnaire. In this study, the average daily acceleration, estimate of global physical activity (total volume), without intensities thresholds, was $23.4 \mathrm{mg}$ among men and $23.1 \mathrm{mg}$ among women. These results are similar to our findings in terms of daily volume of physical activity and the absence of differences between men and women. Further comparisons also might be carried out with data from a methodological study, which provided descriptive data from three studies from different countries among adults. The average daily acceleration in United Kingdom (mean of age: 50.3 years), Kuwait (mean of age: 43.0 years) and Cameroon (mean of age: 40.3 years) were $31.8 \mathrm{mg}$, $24.6 \mathrm{mg}$ and $34.5 \mathrm{mg}$, respectively.

It is also important to highlight effect of applying different bout criteria to data summarize in $5 \mathrm{~s}$ epoch. Time spent in MVPA decreased about 45\%, 19\% and $11 \%$ when 1, 5 and 10-min bout were used, respectively. This observation corroborates prior findings in adult populations $[16,23]$ suggesting that the use of different

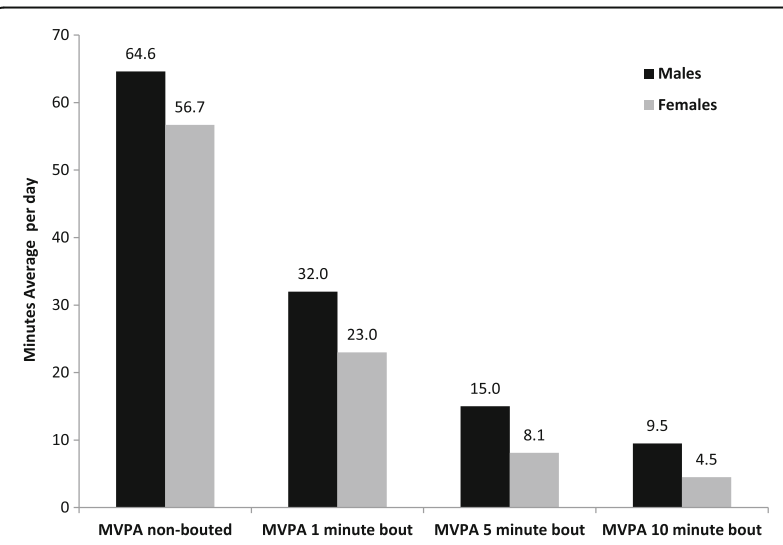

Fig. 2 Average minutes per day spent in MVPA according to different bout criteria among older adults according to sex- Pelotas/Brazil, 2014 bout criteria considerably affects the final estimate of MVPA. These methodological differences might be even more pronounced among older adults compared to other population groups, especially since older adults are less likely to sustain MVPA for longer periods [24]. Ortileb et al. (2014), for example, found that $47.6 \%$ of older adults participants did not reach at least one 10-min bout of MVPA daily [25]. When applying the WHO physical activity recommendations for public health [26], $35.7 \%$ and $11.9 \%$ of the participants achieved guidelines when no bout and 10-min bout criteria were applied, respectively.

In addition, intermittent exercises, which do not necessarily reach the bout criteria, may also be important to improve health and quality of life among older adults, as improvements in locomotor and neuromuscular performance [27], aerobic capacity [28], muscular strength and blood pressure [29] have been demonstrated. Therefore, objective methods to assess physical activity should be taken into account bout criteria for this population group, especially when considering that older adults tend to perform shorter duration exercises [9].

Previous accelerometer-based studies suggest a decrease in physical activity by increasing age $[3,21,30,31]$. Although all reasons are not exactly identified (30), it might be due to difficulty in mobility, general health status and self-efficacy. Moreover, retirement may decrease transport related physical activity and work related physical activity, which also might be replaced by leisure-time activity [32]. Increase in physical activity between older adults is a relevant factor for improvements on quality of life, especially considering the higher risk of morbidities attributed to aging that can be prevented through an active life style [25].

Despite the existing evidence in the literature considering the wider opportunities and knowledge about physical activity and its relevance, our results showed that those of lower SES were more active in MVPA as compared to higher SES groups. This may partly be explained by differences in transport related physical activity. A recent study from Mexican found an inverse association between active life style and car use, and that lower SES groups walk, cycle or use public 


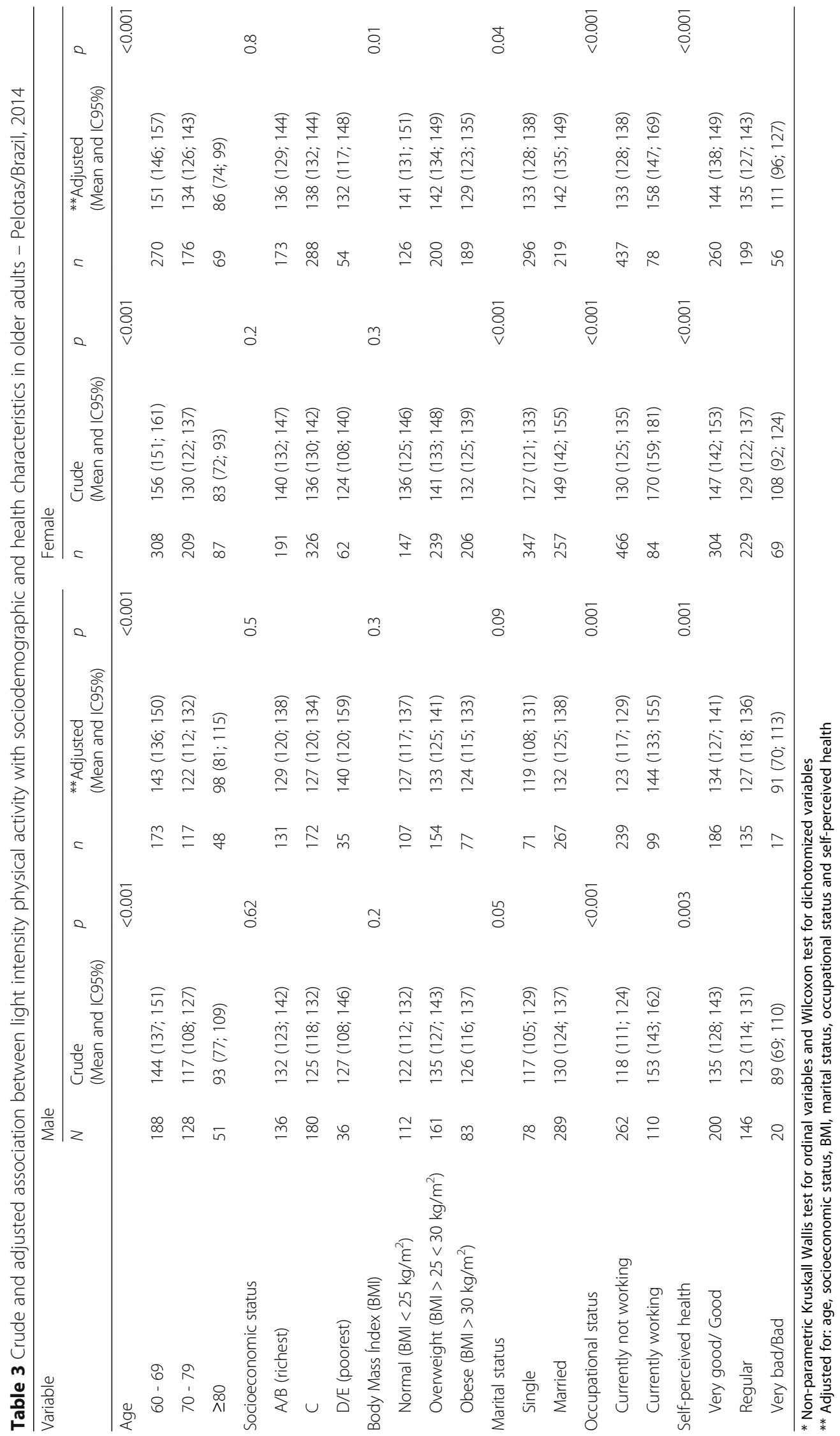




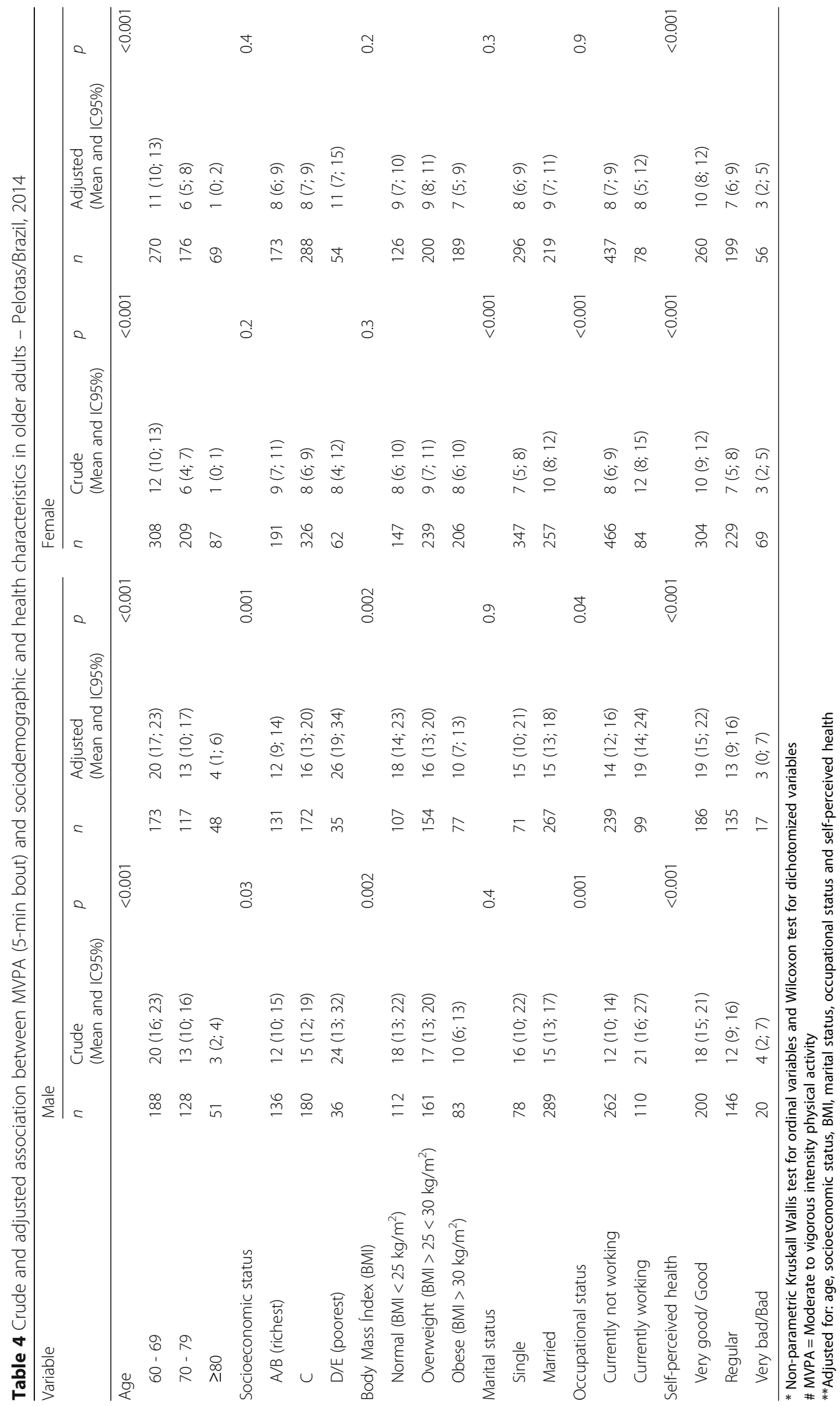


transport when commuting [32]. Another study suggested that lower socioeconomic groups were less active in MVPA which was closely related to the characteristics of their place of residence [33]. Thus, studies examining associations between physical activity and socioeconomic status should consider both the physical activity domains assessed as well as the locations where activity take place. Studies addressing specifically leisure-time activities tend to identify positive associations. On the other hand, studies evaluating overall physical activity, based on accelerometry for example, tend to verify higher heterogeneity and their results, varying according to different settings in which the research was carried out.

The present results should be interpreted considering the following limitations. A third of the participants were not given the opportunity to wear accelerometers due to the limited number of available devices during the period of contact with the older adults population. However, the analytical sample is likely representative of the city of Pelotas, as the missingness was randomly distributed, except for the richest group which is slightly over representated. Furthermore, the cross-sectional nature of the present study preclude causal inference and the association (or lack of association), between physical activity and self-perceived health and BMI might be due to reverse causality.

\section{Conclusions}

The rapid demographic transition which results in population aging, especially in low- and middle-income countries, is characterized by several public health challenges. Participation in physical activity among the older adults is currently an important strategy to prevent chronic diseases and to promote health and quality of life. In this regard, it is relevant to describe physical activity levels measured as accurate as possible, as well as identify specific groups which should be targeted by public health policies. Our results suggest low levels of physical activity in a population-based sample of Brazilian older adults, a substantial reduction in activity lower by more advanced ages, higher levels of activity in lower SES groups and a different pattern of physical activity intensities between men and women.

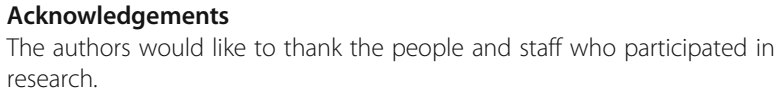

\section{Funding}

This research was supported by the Coordination for the Improvement of Higher Level -or Education- Personnel [1107/2013]. The work of UE and SB were funded by the UK Medical Research Council [MC_UU_12015/3].

\section{Availability of data and materials}

The dataset supporting of this article are available upon request to the corresponding author.

\section{Authors' contributions}

WR, ICMS, AWB and LG performed the analyses and wrote this paper. FCW, UE and SB collaborated in the analyses process and critical revision of the manuscript. All authors read and approved the final version of the manuscript.

\section{Competing interests}

The authors declare that they have no competing interests

\section{Consent for publication \\ Not applicable.}

\section{Ethics approval and consent to participate}

The present study was submitted and approved by the Ethics Research Committee of the Medical School of the Federal University of Pelotas according to the protocol number 201324538513.1.0000.5317. The confidentiality was guaranteed for all individual information and all participants signed the research consent.

\section{Author details}

${ }^{1}$ Postgraduate Program in Epidemiology, Federal University of Pelotas, Marechal Deodoro, 1160 - 3 Piso, Centro, 96020-220, Pelotas, Brazil. ${ }^{2}$ Federal Institution for Education, Science and Technology, Camaquã Campus, Camaquã, Brazil. ${ }^{3}$ Research Group in Accelerometry-based Physical Activity, Pelotas, Brazil. ${ }^{4}$ Postgraduate Program in Physical Education, Federal University of Pelotas, Pelotas, Brazil. ${ }^{5}$ Medical Research Council Epidemiology Unit, University of Cambridge, Cambridge, UK. ${ }^{6}$ Norwegian School of Sports Science, Oslo, Norway. ${ }^{7}$ International Center of Equity in Health, Postgraduate Program in Epidemiology, Federal University of Pelotas, Pelotas, Brazil.

Received: 24 October 2016 Accepted: 6 January 2017

Published online: 02 February 2017

\section{References}

1. Hallal PC, Andersen LB, Bull FC, Guthold R, Haskell W, Ekelund U. Global physical activity levels: surveillance progress, pitfalls, and prospects. Lancet (London, England). 2012;380(9838):247-57.

2. Lee IM, Shiroma EJ, Lobelo F, Puska P, Blair SN, Katzmarzyk PT. Effect of physical inactivity on major non-communicable diseases worldwide: an analysis of burden of disease and life expectancy. Lancet (London, England). 2012;380(9838):219-29.

3. Lohne-Seiler H, Hansen BH, Kolle E, Anderssen SA. Accelerometerdetermined physical activity and self-reported health in a population of older adults (65-85 years): a cross-sectional study. BMC Public Health. 2014; 14:284.

4. Gulsvik AK, Thelle DS, Samuelsen SO, Myrstad M, Mowe M, Wyller TB. Ageing, physical activity and mortality-a 42-year follow-up study. Int Epidemiol. 2012;41(2):521-30

5. WHO World Health Organization. Global Health and Ageing. Geneva: WHO World Health Organization; 2011.

6. Prince SA, Adamo KB, Hamel ME, Hardt J, Connor Gorber S, Tremblay M. A comparison of direct versus self-report measures for assessing physical activity in adults: a systematic review. Int J Behav Nutr Phys Act. 2008;5:56.

7. Janz KF. Physical activity in epidemiology: moving from questionnaire to objective measurement. Br J Sports Med. 2006;40(3):191-2.

8. Dyrstad SM, Hansen BH, Holme IM, Anderssen SA. Comparison of selfreported versus accelerometer-measured physical activity. Med Sci Sports Exerc. 2014;46(1):99-106.

9. Harada ND, Chiu V, King AC, Stewart AL. An evaluation of three self-report physical activity instruments for older adults. Med Sci Sports Exerc. 2001; 33(6):962-70.

10. Espana-Romero V, Golubic R, Martin KR, Hardy R, Ekelund U, Kuh D, et al. Comparison of the EPIC Physical Activity Questionnaire with combined heart rate and movement sensing in a nationally representative sample of older British adults. PloS One. 2014;9(2):e87085.

11. Sabia S, Cogranne P, van Hees VT, Bell JA, Elbaz A, Kivimaki M, et al. Physical activity and adiposity markers at older ages: accelerometer vs questionnaire data. J Am Med Dir Assoc. 2015;16(5):438.e7-13.

12. Troiano RP, McClain JJ, Brychta RJ, Chen KY. Evolution of accelerometer methods for physical activity research. Br J Sports Med. 2014;48(13):1019-23. 
13. Instituto Brasileiro de Geografia e Estatística - IBGE. Censo Demográfico 2010: Características da população e dos domicílios. Rio de Janeiro, Brasil. 2011. http://biblioteca.ibge.gov.br/visualizacao/periodicos/93/cd_2010_ caracteristicas_populacao_domicilios.pdf. Accessed 10 Oct 2016.

14. World Health Organization - WHO. Proposed working definition of an older person in Africa for the MDS Project. http://www.who.int/healthinfo/survey/ ageingdefnolder/en/. Accessed 10 Oct 2016.

15. Chumlea WC, Guo S. Equations for predicting stature in white and black elderly individuals. J Gerontol. 1992;47(6):M197-203.

16. da Silva IC, van Hees VT, Ramires W, Knuth AG, Bielemann RM, Ekelund U, et al. Physical activity levels in three Brazilian birth cohorts as assessed with raw triaxial wrist accelerometry. Int J Epidemiol. 2014;43(6):1959-68.

17. van Hees VT, Gorzelniak L, Dean Leon EC, Eder M, Pias M, Taherian S, et al. Separating movement and gravity components in an acceleration signal and implications for the assessment of human daily physical activity. PloS One. 2013;8(4):e61691.

18. van Hees VT, Fang Z, Langford J, Assah F, Mohammad A, da Silva IC, et al. Autocalibration of accelerometer data for free-living physical activity assessment using local gravity and temperature: an evaluation on four continents. J Appl Physiol (Bethesda, Md 1985). 2014;117(7):738-44.

19. Hildebrand M, Vanh VT, Hansen BH, Ekelund U. Age group comparability of raw accelerometer output from wrist- and hip-worn monitors. Med Sci Sports Exerc. 2014;46(9):1816-24.

20. Associação Brasileira de Empresas de Pesquisa - ABEP. Critério de Classificação Econômica Brasil. São Paulo 2014. www.abep.org/Servicos/ Download.aspx?id=01. Accessed 15 Sept 2016.

21. Buman MP, Hekler EB, Haskell WL, Pruitt L, Conway TL, Cain KL, et al. Objective light-intensity physical activity associations with rated health in older adults. Am J Epidemiol. 2010;172(10):1155-65.

22. Wijndaele K, Westgate K, Stephens SK, Blair SN, Bull FC, Chastin SF, et al. Utilization and harmonization of adult accelerometry data: review and expert consensus. Med Sci Sports Exerc. 2015;47(10):2129-39.

23. Orme M, Wijndaele K, Sharp SJ, Westgate K, Ekelund U, Brage S. Combined influence of epoch length, cut-point and bout duration on accelerometryderived physical activity. Int J Behav Nutr Phys Act. 2014;11(1):34.

24. Aoyagi Y, Shephard RJ. Habitual physical activity and health in the elderly: the Nakanojo Study. Geriatr Gerontol Int. 2010;10 Suppl 1:S236-43.

25. Sun F, Norman IJ, While AE. Physical activity in older people: a systematic review. BMC Public Health. 2013;13:449.

26. WHO World Health Organization. Global recommendations on physical activity for health. Geneva: WHO World Health Organization; 2010.

27. Thomas EE, De Vito G, Macaluso A. Speed training with body weight unloading improves walking energy cost and maximal speed in 75- to 85-yearold healthy women. J Appl Physiol (Bethesda, Md 1985). 2007;103(5):1598-603.

28. Lepretre PM, Vogel T, Brechat PH, Dufour S, Richard R, Kaltenbach G, et al. Impact of short-term aerobic interval training on maximal exercise in sedentary aged subjects. Int J Clin Pract. 2009;63(10):1472-8.

29. Nemoto K, Gen-no H, Masuki S, Okazaki K, Nose H. Effects of high-intensity interval walking training on physical fitness and blood pressure in middleaged and older people. Mayo Clin Proc. 2007;82(7):803-11.

30. Corder K, Ogilvie D, van Sluijs EM. Invited commentary: Physical activity over the life course-whose behavior changes, when, and why? Am J Epidemiol. 2009;170(9):1078-81. discussion 82-3.

31. Jefferis BJ, Sartini C, Ash S, Lennon LT, Wannamethee SG, Lee IM, et al. Trajectories of objectively measured physical activity in free-living older men. Medicine and science in sports and exercise. 2015;47(2):343-9.

32. Salvo D, Torres C, Villa U, Rivera JA, Sarmiento OL, Reis RS, et al. Accelerometer-based physical activity levels among Mexican adults and their relation with sociodemographic characteristics and BMl: a crosssectional study. Int J Behav Nutr Phys Act. 2015;12:79.

33. Lindgren M, Borjesson M, Ekblom O, Bergstrom G, Lappas G, Rosengren A. Physical activity pattern, cardiorespiratory fitness, and socioeconomic status in the SCAPIS pilot trial - A cross-sectional study. Prev Med Rep. 2016;4:44-9.

\section{Submit your next manuscript to BioMed Central and we will help you at every step:}

- We accept pre-submission inquiries

- Our selector tool helps you to find the most relevant journal

- We provide round the clock customer support

- Convenient online submission

- Thorough peer review

- Inclusion in PubMed and all major indexing services

- Maximum visibility for your research

Submit your manuscript at www.biomedcentral.com/submit
( ) BioMed Central 